\title{
Cost Sharing in the Prevention of Supply Chain Disruption
}

\author{
Wen Wang, ${ }^{1}$ Kelei Xue, ${ }^{1}$ and Xiaochen Sun ${ }^{2}$ \\ ${ }^{1}$ Business School, Nankai University, Tianjin 300071, China \\ ${ }^{2}$ College of Science, Tianjin University, Tianjin 300072, China \\ Correspondence should be addressed to Xiaochen Sun; sxc722@163.com
}

Received 5 February 2017; Revised 16 May 2017; Accepted 24 May 2017; Published 28 June 2017

Academic Editor: Mauro Gaggero

Copyright (C) 2017 Wen Wang et al. This is an open access article distributed under the Creative Commons Attribution License, which permits unrestricted use, distribution, and reproduction in any medium, provided the original work is properly cited.

\begin{abstract}
We examine the influence of cost-sharing mechanism on the disruption prevention investment in a supply chain with unreliable suppliers. When a supply chain faces considerable loss following a disruption, supply chain members are motivated toward investing in manners that reduce their disruption probability. In improving supply chain reliability, the cost-sharing mechanism must be set appropriately to realize the efficiency of the disruption prevention investment. In a supply chain where the focal manufacturing company has its own subsidiary supplier and an outsourcing supplier, we analyze different forms of cost-sharing mechanisms when both suppliers confront disruption risks. Through the cost-sharing mechanisms presented in this study, supply chain members can improve their reliability via disruption prevention investments without considerably increasing the total supply chain cost. We present two concepts, the cost-sharing structure and the cost-sharing ratio, in this study. As the two key components of cost-sharing mechanism, these two elements constitute a practicable cost allocation mechanism to facilitate disruption prevention.
\end{abstract}

\section{Introduction}

Disruptions have severe consequences that result in immense costs in today's globalized supply chains. The supply chain becomes increasingly vulnerable as it enjoys decreased costs from outsourcing and lean production. Intensified by globalization, disruption threats can arise from multiple sources. Natural hazards and man-made errors may all cause disruption. In 2000, a fire caused by lightning at Philip's semiconductor plant induced an interruption of the supply of key components to Ericsson. This interruption eventually led to Ericsson's exit from the mobile phone device market. The Japanese earthquake in March 2011 caused global supply disruptions in numerous industries. The total worldwide economic effect in the automotive industry of these disruptions is estimated to amount to US $\$ 139$ billion [1, 2]. In [3], Hendricks and Singhal provide empirical evidence that supply chain disruptions significantly influence the financial performance of firms. On average, firms which experienced disruptions suffered $40 \%$ loss in stock return. Owing to the disastrous aftermaths of supply disruptions, firms eagerly seek mitigation methods to remit the impact of interruptions. Operational approaches such as multisourcing, backup sourcing, and insurance purchase are all efficient methods allowing companies to address disruption risks. Such approaches primarily emphasize the mitigation of disruption without considering the possibility of improving the reliability of the supply chain members. However, it is feasible for companies to prevent disruptions and to minimize their probability. Firms can invest in their own production processes to reduce the probability of supply disruption.

In August 2016, a severe product safety crisis occurred when Samsung introduced their newest mobile phone model, Galaxy Note 7. Numerous users reported that their mobile phone devices caught fire and exploded while charging. The overheating of the device was revealed to be caused by its defective battery. Consequently, Samsung announced a mass defective production recall and provided new product replacements. However, the replacement devices still failed to remedy the battery defects. Samsung then recalled all the devices (replacements included) and ceased production of the Note 7 by November 2016. Instead of being a hit, Note 7, as the most appealing flagship product of Samsung's mobile devices, came to its end. As the entire supply chain broke down, the revenue loss for Samsung from this crisis is estimated at US\$17 billion of business income. Furthermore, the damage to the company's brand is yet to be evaluated. 
Out of the above-mentioned crises, the battery supply chain of Samsung attracted people's attention. Two main battery suppliers were involved for Note 7: Samsung's subsidiary company SDI and a Chinese battery firm ALT. When it first announced a device replacement, Samsung declared ALT as the qualified supplier of a safe product. In this practical case, both suppliers of Samsung failed to deliver quality batteries, ultimately causing substantial loss for both the suppliers and the focal corporation. Setting aside the conflict between the technology bottleneck of battery capacity and the higher requirements from the mobile company, the suppliers could have reduced certain production disruption risks through technology investment or production error detection. Thus, it is essential for suppliers to consider the possible disruption costs when formulating their production decisions. Doing so allows them to participate in self-development activities and to invest in reliability improvements.

The problem investigated in this study is enlightened by the case of the Samsung crisis. In this scenario where a focal company with two upstream suppliers faces the risk of disruption, a disruption cost allocation mechanism should be established, thereby enabling the suppliers to internalize the possible disruption loss of the entire supply chain. In doing so, when disruptions arise because of the suppliers, both the losses of their own business income and the focal company are considered. The suppliers need to formulate their own production investment decisions concerning the entire supply chain. In this study, we present a cost-sharing mechanism characterized by two key components, namely, the sharing structure and the sharing ratio. We analyze two types of allocation structures: united cost sharing and divided cost sharing. Specifically, in the allocation mechanism with a united cost-sharing structure, the suppliers share the cost of the supply chain whenever disruption transpires, regardless of which party is actually responsible for the disruption. Conversely, with the divided sharing structure, the suppliers share the supply chain costs only when they are both disrupted; however, the party solely responsible for the disruption bears the cost of the entire supply chain. Moreover, this study investigates how suppliers under each cost-sharing structure should further distribute the shared cost by presenting the other main concept of the allocation rule, that is, the costsharing ratio. We analyze two types of sharing ratios: fixed and variable ratios. The shared cost is distributed either by a fixed or by a variable ratio depending on the disruption prevention effort of the suppliers.

The remainder of this study is organized as follows. Section 2 briefly reviews related literature. In Section 3, we introduce the supply chain structure of this study and present the problem description. In Section 4, we introduce the model used to characterize the cost-sharing problem in the supply chain when two suppliers face disruption risks. Section 5 provides the numerical evidence for the results and the managerial insights. Finally, Section 6 presents the conclusions and future research directions.

\section{Literature Review}

How to deal with the supply chain disruption risk has now become an essential theme in the realm of operations management. The disruption events could happen at supply end, in the process of production, or at the demand end of the supply chain. Multiple methods, including operational approach as well as financial approach, could be used in coping with the risk of disruptions. This paper studies the disruption investment of suppliers and the cost-sharing mechanism in the supply chain. We focus our literature review in the field of supply disruption risk management and supply chain investment.

The production form of supply chain could reduce the manufactures' operation cost significantly, although this could also induce higher vulnerability in the production process. The risk of disruption from supply end has been intensified by the globalization economics. Chopra and Sodhi [4] present multiple sources of supply disruption. How to locate the appropriate method to cope with supply disruption risks has drawn major attention of the researchers and the practitioners. When applying operational mitigation, multiple-sourcing, and backup production can be used to deal with supply disruptions [5]. When facing supply risks, researches have been done to investigate supplier selection and the order distribution among the risky suppliers [6]. When the suppliers' reliability state is private information, it is possible for the suppliers to use the information sharing as a competition strategy [7]. Other mitigation methods like financial mitigation strategies are widely discussed [8].

Former researches focus on the mitigation strategies to reduce the influence of disruptions. They mainly pay attention to mitigating the impact on firms' revenue loss. Most of the studies work upon the basic assumption that the supply chain disruption probability could not be changed by the members' efforts. Yet through certain investment activities, the suppliers' reliability could actually be improved. Krause et al. [9] gives empirical evidence showing that the supplier development could be achieved by the direct involvement of the firms. Tang et al. [10] investigate the incentives buyers could use to encourage the suppliers' investment in mitigating disruption. By adopting the endogenous supplier disruption probability, they study both direct involvement of subsidy to supplier and the indirect approach of inflation order. Bakshi and Kleindorfer [11] in their paper investigate coopetition and investment in a one-supplier and one-retailer supply chain. Considering the supplier's reliability level as private information, they use the Harsanyi-Selten-Nash bargaining framework to study the information asymmetry problem. They present an incentive-compatible contract which leads to optimal supply chain investment. This paper adopts the disruption probability characterization from their paper. However, our study differs from theirs distinctively. We investigate a different supply chain configuration with two risky suppliers. And we focus on the design and analysis of the cost-sharing mechanism, trying to find the efficient method to allocate the disruption cost. Kim and Tomlin [12] study the investments dealing with disruption in the compound system. They show how the firm should balance between the effort of failure prevention and recovery capacity when the subsystems could reinforce their own capability in resisting disruption. As they investigate the cascading failure between the subsystems, disruption penalty allocation rule is also of 
their research scope. Tomlin also studies different disruption mitigation strategies for multiple unreliable suppliers in [13].

Different than the former researches, in our paper, the disruption probability is not unchangeable. The suppliers can participate in their production process and develop activities to improve their reliability. We also focus on the supply chain disruption cost-sharing problem and analyze the performance of different mechanism structures.

\section{Problem Description}

In this study, we investigate the suppliers' investments in disruption prevention and on the disruption cost-sharing problem. Using game theory models, we attempt to locate the suppliers' investment strategies in equilibrium. In this section, we introduce the investigated supply chain. Two firms are involved in the supply chain, the focal manufacturing company with its own subsidiary supply company (Firm 1) and the outsourcing company working as the supplier of the focal company (Firm 2). Both firms face the risk of disruption. We also assume that the two supplier disruption events are independent of each other. This assumption indicates that when the supply chain is disrupted, the cause can be attributed to the breakdown of only one supplier or both suppliers. Disruption from either supplier could result in a significant loss to the entire supply chain and thus to all parties in it, as demonstrated by the Samsung crisis. Even if one of the two suppliers can provide suitable components, the focal company still has to contend with the damage caused by the defective products. Hence, the suppliers should still make certain investments in the operation process in order to reduce their disruption probability. The notations of the variables and parameters used in the subsequent analysis are as follows:

$y_{1}$ : the disruption prevention investment of Firm 1, the subsidiary supplier.

$y_{2}$ : the disruption prevention investment of Firm 2, the outsourcing supplier.

$p_{i}(i=1,2)$ : the supplier's disruption probability of firm $i$.

$p_{d}$ : the disruption probability of the supply chain.

$\Pi_{i}$ : the expected cost of firm $i$.

$\Pi^{C}$ : the expected cost of the supply chain in the centralized supply chain.

$\beta$ : the fixed cost-sharing ratio.

$\beta_{c}$ : the changeable cost-sharing ratio.

$C$ : the estimated total cost of the entire supply chain when disruption occurs.

We adopt the exponential functional form characterizing the probability of disruption as a function of the suppliers' investment: $p_{i}=\theta_{i} e^{-\alpha_{i} y_{i}}(i=1,2)$, in which $\theta_{i}$ and $\alpha_{i}$ represent the relative vulnerabilities of supplier $i$. $\theta_{i}$ is the initial disruption probability of the supplier without a prevention investment. As the supplier invests in reliability improvement, its disruption probability decreases. Parameter $\alpha_{i}$ is the accommodation coefficient that operates on the investment, which presents the technique level of the investment efficiency. Furthermore, as we investigate the disruption problem with low probability, we assume that $\theta_{i} \ll 1$. When we consider the independent disruption between the two firms, the joint disruption probability of the supply chain is $p_{d}=1-\left(1-p_{1}\right)\left(1-p_{2}\right)$. The similar assumption and the basic model settings are adopted in [10].

\section{Model Formulation and Analysis}

In this section, we introduce the model formulation of the problem mentioned in the previous section. We first characterize the centralized scenario and then establish the decentralized model under different types of cost-sharing structures.

4.1. Centralized Model. To identify the optimal investment for the supplier disruption prevention in the supply chain, we develop an integral model from the perspective of a central decision maker (usually the focal company, which is the most powerful member of the supply chain). To optimize the total cost of the supply chain, the investments of both suppliers should be decided. We distinguish this scenario using the notation with the superscript $c$. The expected disruption cost of the centralized supply is

$$
\Pi^{c}\left(y_{1}^{c}, y_{2}^{c}\right)=y_{1}^{c}+y_{2}^{c}+p_{d}^{c} C \text {. }
$$

The total cost of the centralized supply chain as jointly convex in the suppliers' investments is easily verified. We can determine the optimal investment strategies of the suppliers as shown in the following proposition.

Proposition 1. In a supply chain with a central decision maker, we can identify the optimal investments of the two suppliers as follows:

$$
\begin{aligned}
& p_{i}^{c *} \\
& =\frac{\left(-\alpha_{i}+\alpha_{j}+\alpha_{i} \alpha_{j} C\right)-\sqrt{\left(\alpha_{i}-\alpha_{j}-\alpha_{i} \alpha_{j} C\right)^{2}-4 \alpha_{i} \alpha_{j}^{2} C}}{2 \alpha_{i} \alpha_{j} C}, \quad(i, j=1,2, i \neq j) \\
& y_{i}^{c *}=-\frac{1}{\alpha_{i}} \ln \left(\frac{p_{i}^{c *}}{\theta_{i}}\right), \quad(i=1,2) .
\end{aligned}
$$

We use the centralized system as the benchmark of the following analysis. From the solution, we can see that the optimal supplier investment is increased with higher technique level of the investment efficiency and has the positive correlation with the supplier's initial disruption probability.

4.2. Nash Equilibrium Model. In this section, we develop a Nash game model to analyze the investments of the suppliers when all the suppliers make their decisions simultaneously. We present two cost-sharing structures in this section: the divided and united cost-sharing structures. 
4.2.1. Divided Cost-Sharing Structure. Depending on which party is actually responsible for the supply chain disruption, the total cost of the supply chain disruption could be classified into three types: disruption solely caused by the subsidiary supplier's failure, disruption solely caused by the outsourcing supplier's failure, and disruption caused by the failure of both suppliers. In the divided cost-sharing structure, a supplier bears the disruption cost when it is solely responsible for the disruption. The portion of the disruption cost due to both suppliers is distributed between them according to the costsharing ratio. The expected disruption losses for both firms are modeled below:

$$
\begin{aligned}
& \Pi_{1}=y_{1}+p_{1}\left(1-p_{2}\right) C+\beta p_{1} p_{2} C \\
& \Pi_{2}=y_{2}+\left(1-p_{1}\right) p_{2} C+(1-\beta) p_{1} p_{2} C
\end{aligned}
$$

The strategy space of the suppliers is evidently compact and concave in this game. Hence, the payoff function is continuous and convex with respect to the strategy of each player. Therefore, equilibrium exists.

Proposition 2. Under the divided cost-sharing structure, we can obtain the Nash equilibrium solution for the investments of the suppliers with the fixed cost-sharing ratio:

$$
\begin{aligned}
& p_{1}^{*}=\frac{\left[-(1-\beta) \alpha_{1}+\beta \alpha_{2}+\alpha_{1} \alpha_{2} C\right]-\sqrt{\left[-(1-\beta) \alpha_{1}+\beta \alpha_{2}+\alpha_{1} \alpha_{2} C\right]^{2}-4 \beta \alpha_{1} \alpha_{2}{ }^{2} C}}{2 \beta \alpha_{1} \alpha_{2} C}, \\
& p_{2}^{*}=\frac{\left[(1-\beta) \alpha_{1}-\beta \alpha_{2}+\alpha_{1} \alpha_{2} C\right]-\sqrt{\left[(1-\beta) \alpha_{1}-\beta \alpha_{2}+\alpha_{1} \alpha_{2} C\right]^{2}-4(1-\beta) \alpha_{1}^{2} \alpha_{2} C}}{2(1-\beta) \alpha_{1} \alpha_{2} C}, \\
& y_{i}^{*}=-\frac{1}{\alpha_{i}} \ln \left(\frac{p_{i}^{*}}{\theta_{i}}\right), \quad(i=1,2) .
\end{aligned}
$$

In the decentralized system, we can observe the similar attributes of the solution with the centralized system. The corresponding management insights are given in the numerical analysis section.

4.2.2. United Cost-Sharing Structure. Under this type of costsharing structure, whenever disruption occurs, the total cost of the supply chain is shared by the two suppliers. Additionally, the cost-sharing ratio acts on the joint supply chain disruption loss. The expected costs of the two suppliers are as follows:

$$
\begin{aligned}
& \Pi_{1}=y_{1}+\beta p_{d} C, \\
& \Pi_{2}=y_{1}+(1-\beta) p_{d} C .
\end{aligned}
$$

Similarly, we can derive the investments of the suppliers under this cost-sharing structure with the fixed sharing ratio.

Proposition 3. Under the united cost-sharing structure, the Nash equilibrium solution for the investments of the suppliers with the fixed cost-sharing ratio is as follows:

$$
\begin{aligned}
& p_{1}^{*}=\frac{\left[-\beta \alpha_{1}+(1-\beta) \alpha_{2}+\beta(1-\beta) \alpha_{1} \alpha_{2} C\right]-\sqrt{\left[-\beta \alpha_{1}+(1-\beta) \alpha_{2}+\beta(1-\beta) \alpha_{1} \alpha_{2} C\right]^{2}-4 \beta(1-\beta)^{2} \alpha_{1} \alpha_{2}^{2} C}}{2 \beta(1-\beta) \alpha_{1} \alpha_{2} C} \\
& p_{2}^{*}=\frac{\left[\beta \alpha_{1}-(1-\beta) \alpha_{2}+\beta(1-\beta) \alpha_{1} \alpha_{2} C\right]-\sqrt{\left[\beta \alpha_{1}-(1-\beta) \alpha_{2}+\beta(1-\beta) \alpha_{1} \alpha_{2} C\right]^{2}-4 \beta^{2}(1-\beta) \alpha_{1}^{2} \alpha_{2} C}}{2 \beta(1-\beta) \alpha_{1} \alpha_{2} C} \\
& y_{i}^{*}=-\frac{1}{\alpha_{i}} \ln \left(\frac{p_{i}{ }^{*}}{\theta_{i}}\right), \quad(i=1,2) .
\end{aligned}
$$

In this section, we provide the equilibrium solutions to the suppliers' disruption prevention investments for different scenarios of the supply chain configuration. In the succeeding section, we analyze the supply chain performance with numerical evidence for the complexity of the cost function of the suppliers. We also investigate the scenario when the cost-sharing ratio is changeable.

\section{Numerical Analysis}

In this section, we provide the numerical evidence of the costsharing models discussed in Section 4. We likewise present managerial insights for supply chain disruption management with the efficiency analysis of the reliability improvements under different cost-sharing structures. We use the following parameters in Table 1 for this analysis. 
TABLE 1: Parameters for the numerical analysis.

\begin{tabular}{ccccccc}
\hline & $\beta$ & $\theta_{1}$ & $\theta_{2}$ & $\alpha_{1}$ & $\alpha_{2}$ \\
\hline 1 & 0.3 & 0.03 & 0.05 & 0.00003 & 0.00004 & 0.00004 \\
2 & 0.5 & 0.03 & 0.05 & 0.00003 & 0.00004 & 5000000 \\
3 & 0.7 & 0.03 & 0.05 & 0.00003 & 0.0004 & 50000000 \\
4 & 0.7 & 0.03 & 0.05 & 0.0003 & 0.00004 & 5000000 \\
5 & 0.7 & 0.20 & 0.30 & 0.00003 & 0.00004 & 5000000 \\
6 & 0.7 & 0.03 & 0.05 & 0.00003 & 10000000 \\
\hline
\end{tabular}

TABLE 2: Centralized system.

\begin{tabular}{lcccccc}
\hline & $y_{1}$ & $y_{2}$ & $p_{1}$ & $p_{2}$ & $p_{d}$ \\
\hline $1-3$ & 49968 & 57397 & 0.00670039 & 0.00503373 & 0.0117004 & 165866 \\
4 & 12687 & 11511 & 0.000667 & 0.00050033 & 0.001167 & 30034 \\
5 & 113205 & 102191 & 0.00670039 & 0.00503373 & 0.0117004 & 273898 \\
6 & 73157 & 74810 & 0.00334172 & 0.00250838 & 0.00584172 & 206384 \\
\hline
\end{tabular}

We attempted to analyze different forms of the costsharing mechanism using the above parameter settings. The parameters from Sets 1 to 3 are used to examine the influence of fixed sharing ratio in preventing supply chain disruption. Meanwhile, the parameters of Sets 4 and 5 are employed to inspect the supplier's vulnerability state and its effects on the investments. The last set of parameters is utilized to investigate the influence of total disruption loss.

5.1. Supplier Investments in the Centralized System. We first present the results of the optimal supplier investment strategies in the supply chain with a central decision maker (see Table 2). In this scenario, all the supply chain members are integral, and the optimal disruption prevention investments are achieved.

With these results, we can compare the efficiency of the different cost-sharing structures in the decentralized system. Moreover, we can also perform a rudimentary analysis of the influence of the suppliers' investment on the supply chain disruption.

As indicators of the suppliers' vulnerability, parameters $\alpha_{i}$ and $\theta_{i}$ directly influence the suppliers' investments, as shown in the numerical results for Sets 4 and 5. Based on these two sets, we understand that parameter $\alpha_{i}$ (the coefficient of investment) has a greater impact on the result of the supply chain reliability improvement. In practice, suppliers with further advanced disruption prevention capabilities have increased advantage in reliability improvement. Furthermore, the initial disruption probability of the supplier can affect its investment. However, even with high disruption risks, the supplier can achieve the intended reliability level by investing in disruption prevention.

Numerical results from Set 6 show that when the expected loss from supply chain disruption increases, suppliers will invest more toward disruption prevention activities. Hence, despite a rapidly increasing expected total loss, the total supply loss will remain confined within a reasonable range given the sharply reduced joint disruption probability.
5.2. Supplier Investments in the Decentralized System. We then present the results in the scenario where two firms are developing their own investment strategies in a Nash game. With the fixed sharing ratio, both divided and united costsharing structures are analyzed, and the results are shown in Tables 3 and 4, respectively. Tables 5 and 6 present the results for the two cost-sharing structures with the variable sharing ratio.

From both sets of numerical results, we can formulate key insights on the influence of cost-sharing structures on the efficiency of disruption investment.

(1) With the appropriate sharing mechanism, a decentralized supply chain can increase reliability without a substantial increase in the expected disruption cost.

In the decentralized supply chain, the expected total disruption cost is higher than in the centralized system. Under the united cost-sharing structure, suppliers tend to lessen their investment in disruption prevention. Such decision results in increased vulnerability for the suppliers and the entire supply chain. In the end, the total expected disruption cost rises. Conversely, under the divided costsharing structure, suppliers invest more, thereby improving their reliability. With the reduced vulnerability of suppliers, the joint disruption probability of the supply chain decreases, making it possible to maintain the total expected disruption cost at the same level as the centralized system.

To comprehend this unintuitive outcome, we have to reexamine the model. Under the divided cost-sharing structure, suppliers have to bear the part of the supply chain cost caused by their own failure. Only part of the cost due to the disruption from the failure of both suppliers is shared. Under this rule, the suppliers' motivation regarding disruption prevention is enhanced. Compared with the centralized scenario, under the divided cost-sharing structure the supplier has an enhanced incentive to improve its own reliability. Such intensified motivation will increase prevention investment, which will generate positive externality. The investment from Firm 1 will benefit Firm 2 objectively and vice versa. 
TABLE 3: Equilibrium strategies under the divided cost-sharing structure with the fixed sharing ratio.

\begin{tabular}{ccccccccc}
\hline & $y_{1}$ & $y_{2}$ & $p_{1}$ & $p_{2}$ & $p_{d}$ & $\Pi_{1}$ & $\Pi_{2}$ \\
\hline 1 & 50019 & 57514 & 0.00669013 & 0.00501006 & 0.0116667 & 83352 & 82514 & 165867 \\
2 & 50052 & 57481 & 0.00668343 & 0.00501676 & 0.0116667 & 83386 & 82481 & 165866 \\
3 & 50086 & 57448 & 0.00667673 & 0.00502348 & 0.0116667 & 83419 & 82448 & 165866 \\
4 & 12688 & 11512 & 0.00066677 & 0.00050023 & 0.00116667 & 16022 & 14012 & 30034 \\
5 & 113323 & 102241 & 0.00667673 & 0.00502348 & 0.0116667 & 146656 & 127241 & 273898 \\
6 & 73216 & 74835 & 0.00333584 & 0.00250585 & 0.0058333 & 106549 & 99835 & 206384 \\
\hline
\end{tabular}

TABLE 4: Equilibrium strategies under the united cost-sharing structure with the fixed sharing ratio.

\begin{tabular}{ccccccccc}
\hline & $y_{1}$ & $y_{2}$ & $p_{1}$ & $p_{2}$ & $p_{d}$ & $\Pi_{1}$ & $\Pi_{2}$ & $\Pi_{1}$ \\
\hline 1 & 9759 & 48082 & 0.0223858 & 0.00730642 & 0.0295286 & 54052 & 151432 \\
2 & 26691 & 39897 & 0.0134699 & 0.0101365 & 0.0234699 & 85366 & 98572 \\
3 & 37681 & 27222 & 0.00968684 & 0.0168297 & 0.0263535 & 129918 & 66752 & 183938 \\
4 & 11494 & 8501 & 0.00095397 & 0.00166826 & 0.00262064 & 20667 & 12432 & 33098 \\
5 & 100918 & 72016 & 0.00968684 & 0.0168297 & 0.0263535 & 193156 & 111546 & 304702 \\
6 & 61071 & 44673 & 0.00480212 & 0.00837354 & 0.0131354 & 153020 & 84080 & 237099 \\
\hline
\end{tabular}

TABLE 5: Equilibrium strategies under the divided cost-sharing structure with the variable sharing ratio.

\begin{tabular}{|c|c|c|c|c|c|c|c|c|}
\hline & $y_{1}$ & $y_{2}$ & $p_{1}$ & $p_{2}$ & $p_{d}$ & $\Pi_{1}$ & $\Pi_{2}$ & $\Pi$ \\
\hline $1-3$ & 50105 & 57510 & 0.00667282 & 0.00501091 & 0.0116503 & 83398 & 82469 & 165867 \\
\hline 4 & 12689 & 11512 & 0.00066673 & 0.00050011 & 0.0011665 & 16022 & 14012 & 30034 \\
\hline 5 & 113343 & 102304 & 0.00667282 & 0.00501091 & 0.0116503 & 146635 & 127263 & 273898 \\
\hline 6 & 73226 & 74866 & 0.00333487 & 0.00250272 & 0.00582925 & 106538 & 99846 & 206384 \\
\hline
\end{tabular}

TABLE 6: Equilibrium strategies under the united cost-sharing structure with the variable sharing ratio.

\begin{tabular}{|c|c|c|c|c|c|c|c|c|}
\hline & $y_{1}$ & $y_{2}$ & $p_{1}$ & $p_{2}$ & $p_{d}$ & $\Pi_{1}$ & $\Pi_{2}$ & $\Pi$ \\
\hline $1-3$ & 49999 & 57452 & 0.00669411 & 0.00502265 & 0.0116831 & 83374 & 82493 & 165866 \\
\hline 4 & 12688 & 11512 & 0.00066694 & 0.00050023 & 0.00116683 & 16021 & 14012 & 30034 \\
\hline 5 & 113236 & 102246 & 0.00669411 & 0.00502265 & 0.0116831 & 146611 & 127287 & 273898 \\
\hline 6 & 73173 & 74837 & 0.00334017 & 0.00250564 & 0.00583743 & 106526 & 99858 & 206384 \\
\hline
\end{tabular}

The trade-off between increased investment and decreased expected disruption loss is balanced through the cost-sharing mechanism.

(2) Cost-sharing ratio $\beta$ is essential in the decentralized supply chain. Given the results from Sets 1 to 3, the sharing ratio evidently affects the suppliers' investments and the supply chain's disruption probability. Under the united costsharing structure, the supplier's cost liability proportion primarily depends on the sharing ratio. The supplier with the higher liability proportion will be largely accountable for disruption prevention.

However, with the divided cost-sharing structure, both suppliers tend to exert similar amounts of efforts toward disruption prevention. With the same suppliers' vulnerability parameters, the sharing ratio works as a balance coordinator supporting adjustments to the investment between the two suppliers. Furthermore, the joint disruption probability and the expected disruption loss of the supply chain remain at the same level.

When the cost-sharing ratio is fixed, the decision regarding the specific ratio value is made upon the bargaining power between the two firms. We also analyzed the variable form of the sharing ratio, that is, when the ratio reflects the suppliers' investment outcome. Let $\beta_{c}=p_{1} /\left(p_{1}+p_{2}\right)$ take the place of $\beta$ in the original models. The optimal results under the two cost-sharing structures are shown in Tables 5 and 6.

These results show that the variable sharing ratio further improves the reliability of the supply chain. Under the divided cost-sharing structure, the variable sharing ratio continues to coordinate the supply chain. The supplier adjusts its investment efforts according to the disruption prevention outcome. With the united cost-sharing structure, the variable sharing ratio plays an even more influential role in the supply chain reliability improvement. When the suppliers distribute 


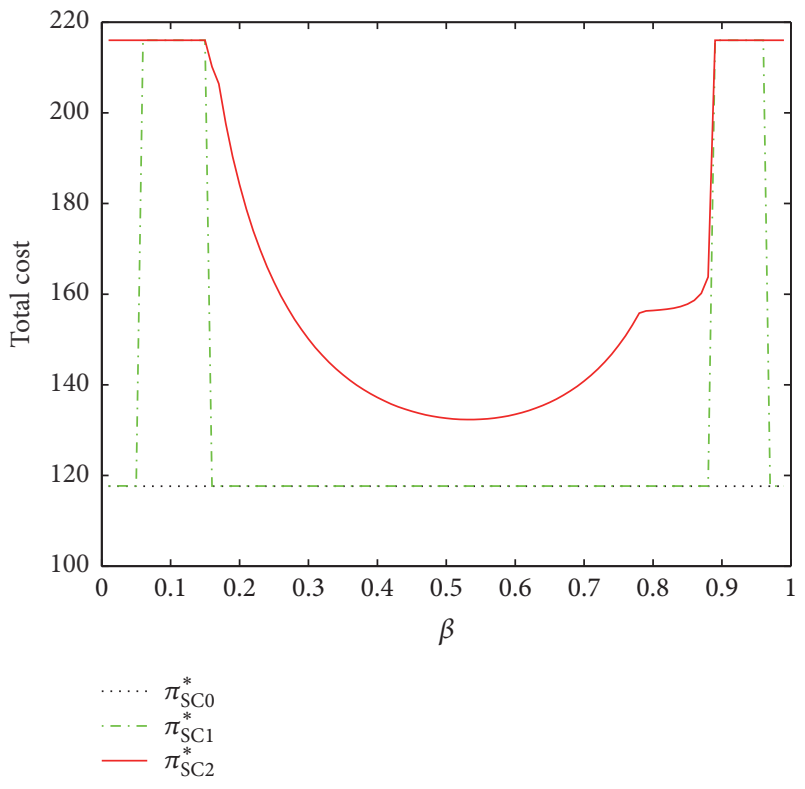

Figure 1: Comparison of the total costs.

the supply chain loss with the variable ratio, the suppliers tend to invest more toward disruption prevention. With decreased disruption probability, the expected supply chain disruption loss will be reduced.

\subsection{Comparison of the Supply Chain Performance between} the Centralized and Decentralized System. After showing the individual attributes of the decision variables in the above two subsections, we now present the whole supply chain performance comparison between centralized and decentralized system. We analyze the supply chain performance with two indicators: the total cost and the disruption probability of the supply chain. The total costs of the supply chain in centralized system, decentralized system with divided cost-sharing structure, and decentralized system with united cost-sharing structure are denoted as $\Pi_{\mathrm{sc} 0}, \Pi_{\mathrm{sc} 1}$, and $\Pi_{\mathrm{sc} 2}$, respectively. The supply chain disruption probabilities in centralized system, decentralized system with divided cost-sharing structure, and decentralized system with united cost-sharing structure are denoted as $p_{d}, p_{d 1}$, and $p_{d 2}$, respectively. The parameters used in this part of analysis are as follows: $\alpha_{1}=0.04 ; \alpha_{2}=$ $0.06 ; \theta_{1}=0.6 ; \theta_{2}=0.3 ; C=300$. The optimal results are shown in Figures 1 and 2.

From these numerical evidences, we can get the key insights on the cost-sharing mechanism performance.

When the fixed cost-sharing ratio $\beta$ is neither too big nor too small, which means the two suppliers are basically equally responsible on the cost-sharing responsibility, the divided cost-sharing structure can reach the performance level of the centralized system. When the fixed cost-sharing ratios are extreme values, which means one of suppliers are mainly responsible for the supply chain disruption cost, divided costsharing structures are on the similar performance level with the united cost-sharing structure.

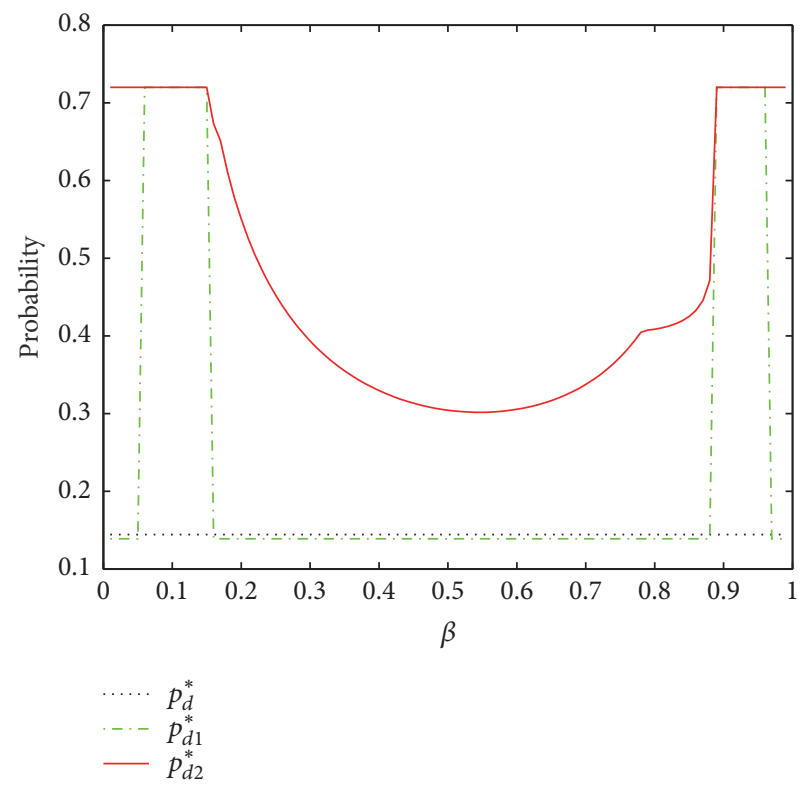

FIGURE 2: Comparison of the supply chain disruption probabilities.

This result shows that when the two suppliers have similar responsibility of the supply chain disruption, they will put more effort into the disruption prevention activities.

We can also find the similar performance pattern of the disruption probability. When both of the suppliers are equally encouraged to invest in disruption prevention activities, when using the divided cost-sharing structure, the total supply chain disruption probability could be even lower than the centralized system. With lower disruption probability, the expected disruption cost will also be lowered. However, with the higher investments, the total cost is on the same level with the centralized system.

\section{Conclusion}

To deal with the increasingly severe consequences of supply chain disruption, the development of efficient methods to reduce the vulnerability of the globalized supply chain becomes an essential undertaking for both researchers and practitioners. In this study, we investigated the problem of disruption loss sharing and prevention investment in a supply chain facing supply risks. When internalizing the expected loss from supply chain disruption, suppliers become motivated to contribute to disruption prevention investment that will influence the entire supply chain. As with their production processes, the suppliers can make certain investments to improve their own reliability. The distribution of the supply chain disruption loss influences the suppliers' investment motive. Therefore, a proper mechanism should be established to achieve the efficiency of the supply chain disruption prevention.

We presented two types of cost-sharing structures in this study: the divided and united cost-sharing structures. The two methods differ from each other mainly in the manner of identifying the accountability for the loss arising from 
the supply chain disruption. In the divided cost-sharing structure, suppliers are responsible for the disruption due to their own failure, but they share the costs incurred from joint failure. In the united sharing structure, suppliers share the supply chain loss whenever disruption occurs. Comparing the two types of cost-sharing structures, we found that supply chain reliability can be efficiently improved without significant increase in investment with the divided sharing structure. The reason is that when motivated by the prospect of being held responsible for their own failure, suppliers will reinforce their disruption prevention activities to reduce their own disruption probability. Such prevention efforts simultaneously benefit the entire supply chain. Without this positive externality, the united cost-sharing structure loses a certain amount of efficiency. Nevertheless, the united sharing structure may still prove to be competitive in practice. Under this structure, the focal company can control outsourcing suppliers by adjusting the cost-sharing ratio given its edge in terms of bargaining power.

The cost-sharing ratio is the other key part of the costsharing mechanism. Under each sharing structure, the shared part of disruption loss is distributed between the two firms according to this ratio. With the fixed sharing ratio, the focal company can manipulate the investments of the outsourcing firm under the united sharing structure. However, the variable sharing ratio can coordinate to balance the suppliers' investments. The reason for such function is that when the sharing ratio is changing along with the outcome of the prevention investments, the suppliers' motivation of improving their own reliability is strengthened.

By presenting different forms of the cost-sharing mechanism, we investigated the problem of the suppliers' investments in supply chain disruption prevention. Using the appropriate allocation rule to distribute the supply chain disruption loss enhances the suppliers' motivation to improve their own reliability, thereby reducing the expected disruption cost of the entire supply chain.

Further exploration is warranted in the supply chain disruption prevention. Future research that considers the manufacturer's disruption risk and studies the interactive influence among the supply chain members represents one direction. In this study, we focused on the analysis of the cost-sharing mechanism, and we considered the loss of the supply chain disruption as an exogenous parameter. Characterizing the interrelationship between disruption losses and prevention efforts can be interesting as well. Moreover, both of the suppliers' vulnerability states are considered as common knowledge in this study. Considering the reliability of suppliers through their private information and analyzing such information asymmetry scenario are another direction for future research.

\section{Conflicts of Interest}

The authors declare that there are no conflicts of interest regarding the publication of this article.

\section{Acknowledgments}

This work was supported by the National Natural Science Foundation of China (no. 71572125).

\section{References}

[1] I. Arto, V. Andreoni, and J. M. Rueda Cantuche, "Global impacts of the automotive supply chain disruption following the Japanese earthquake of 2011," Economic Systems Research, vol. 27, no. 3, pp. 306-323, 2015.

[2] C. A. MacKenzie, J. R. Santos, and K. Barker, "Measuring changes in international production from a disruption: case study of the Japanese earthquake and tsunami," International Journal of Production Economics, vol. 138, no. 2, pp. 293-302, 2012.

[3] K. B. Hendricks and V. R. Singhal, "An empirical analysis of the effect of supply chain disruptions on long-run stock price performance and equity risk of the firm," Production \& Operations Management, vol. 14, no. 1, pp. 35-52, 2005.

[4] S. Chopra and M. S. Sodhi, "Reducing the risk of supply chain disruptions," MIT Sloan Management Review, vol. 55, no. 3, pp. 73-80, 2014.

[5] Z. B. Yang, G. Aydın, V. Babich, and D. R. Beil, "Supply disruptions, asymmetric information, and a backup production option," Management Science, vol. 55, no. 2, pp. 192-209, 2009.

[6] P. D. Berger, A. Gerstenfeld, and A. Z. Zeng, "How many suppliers are best? A decision-analysis approach," Omega, vol. 32, no. 1, pp. 9-15, 2004.

[7] M. Gümüş, S. Ray, and H. Gurnani, "Supply-side story: risks, guarantees, competition, and information asymmetry," Management Science, vol. 58, no. 9, pp. 1694-1714, 2012.

[8] B. Tomlin, "On the value of mitigation and contingency strategies for managing supply chain disruption risks," Management Science, vol. 52, no. 5, pp. 639-657, 2006.

[9] D. R. Krause, R. B. Handfield, and B. B. Tyler, "The relationships between supplier development, commitment, social capital accumulation and performance improvement," Journal of Operations Management, vol. 25, no. 2, pp. 528-545, 2007.

[10] S. Y. Tang, H. Gurnani, and D. Gupta, "Managing disruptions in decentralized supply chains with endogenous supply process reliability," Production and Operations Management, vol. 23, no. 7, pp. 1198-1211, 2014.

[11] N. Bakshi and P. Kleindorfer, "Coopetition and investment for supply-chain resilience," Production and Operations Management, vol. 18, no. 6, pp. 583-603, 2009.

[12] S.-H. Kim and B. Tomlin, "Guilt by association: strategic failure prevention and recovery capacity investments," Management Science, vol. 59, no. 7, pp. 1631-1649, 2013.

[13] B. Tomlin, "Disruption-management strategies for short lifecycle products," Naval Research Logistics, vol. 56, no. 4, pp. 318347, 2009. 


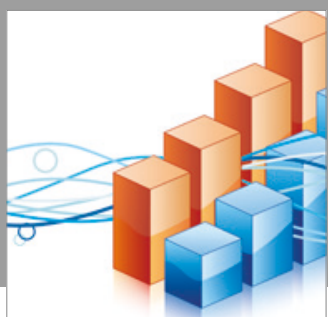

Advances in

Operations Research

vatersals

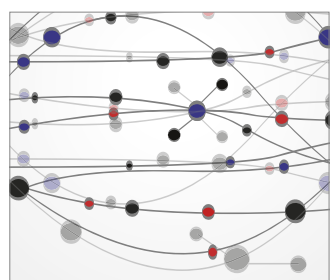

\section{The Scientific} World Journal
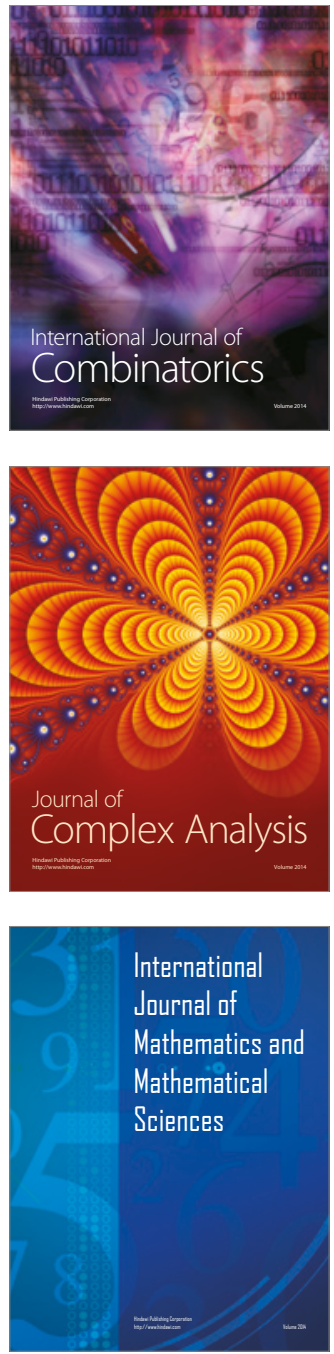
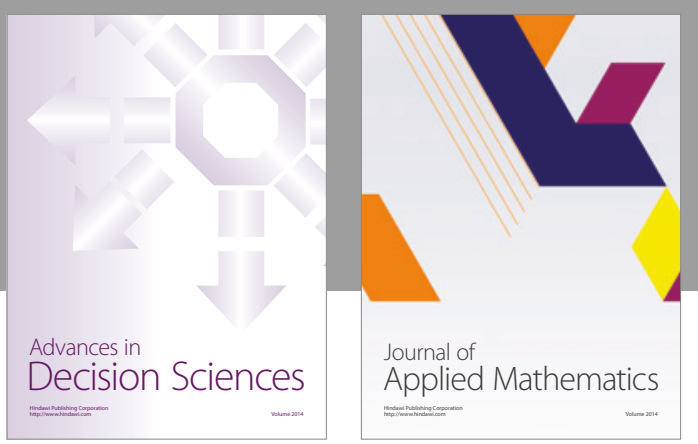

Algebra

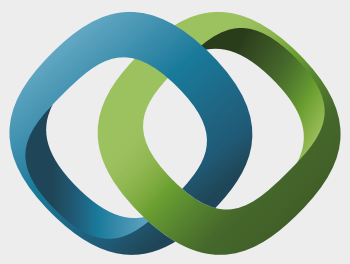

\section{Hindawi}

Submit your manuscripts at

https://www.hindawi.com
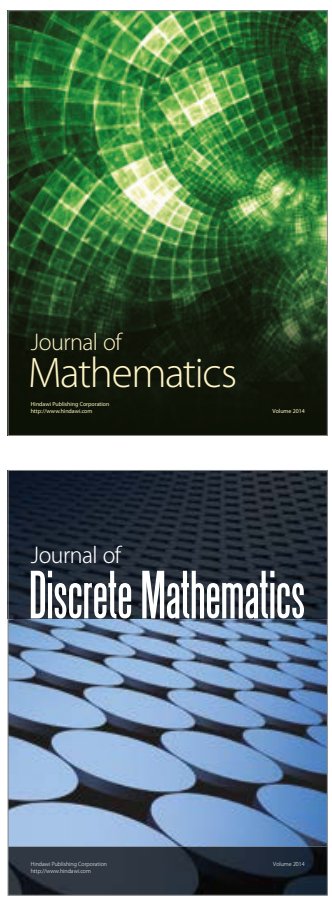

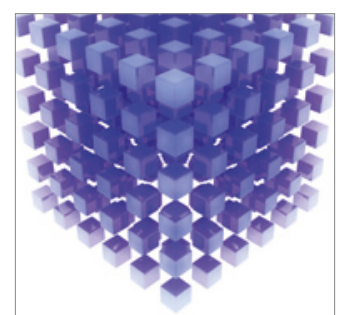

Mathematical Problems in Engineering
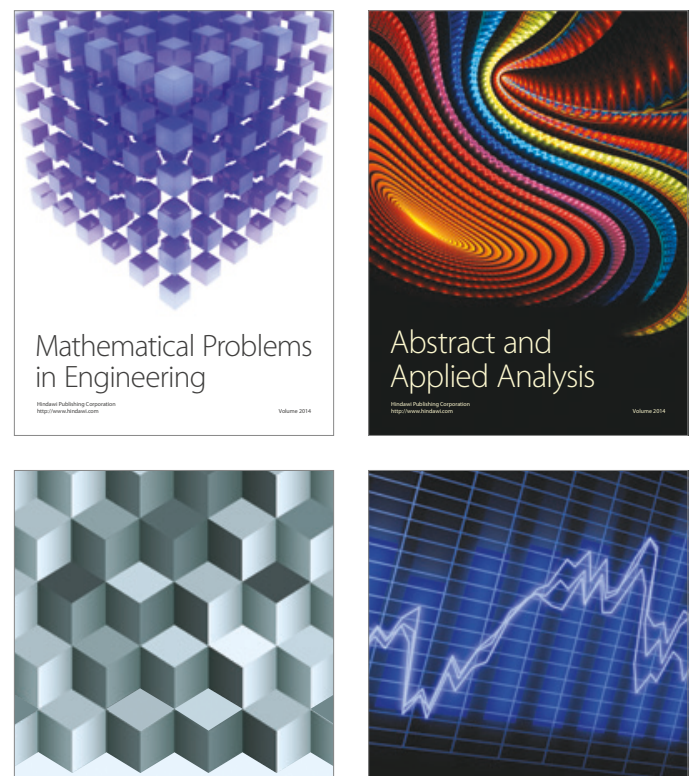

Journal of

Function Spaces

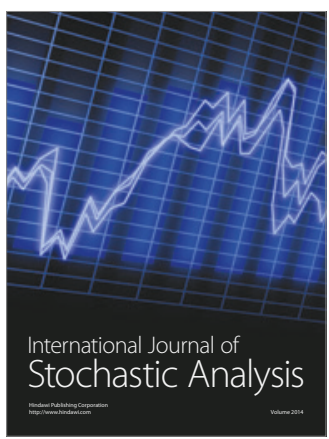

Probability and Statistics
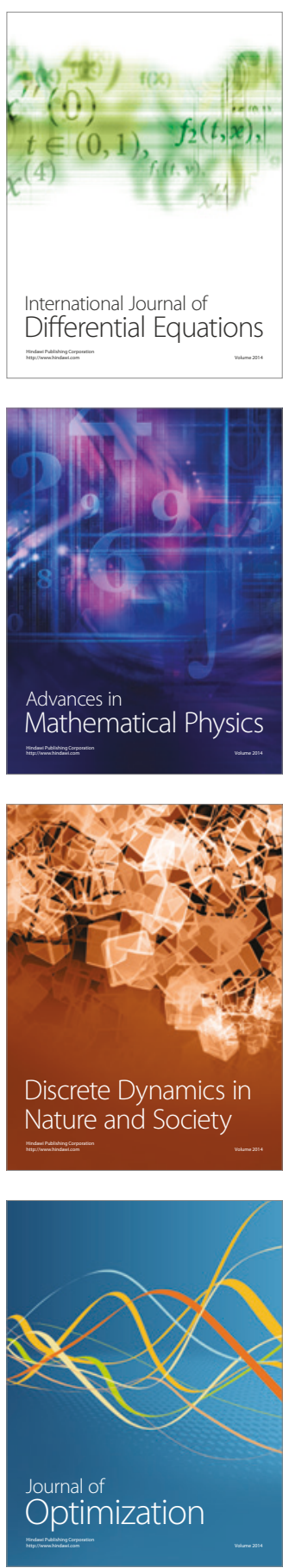